\title{
The aesthetic experience: Project on perception and sound and plastic sensitivity
}

\author{
Magdalena Jaume-Adrover ${ }^{1 a}$, Noemy Berbel-Gómez ${ }^{1}$ \\ ${ }^{1}$ University of the Balearic Islands, Cra. de Valldemossa Km 7.5, Palma de Mallorca 07122, Spain
}

\begin{abstract}
Light and shadow, sounds and silence, movement and stability have been, since the origin of art, basic, elementary features in every work. They are the material that John Cage, Merce Cunninham, Bob Wilson, László Moholy-Nagy, Alexander Calder, and Llorenç Barber work with. All of whom stand out because of their will to expand the perceptive capacity of the beholder. In the subject of Artistic Projects for Early Childhood Education we have taken some of their works as the starting point of each of the educational projects, posed by pupils. Our aim is not to teach art to boys and girls, or to teach them to appreciate or to recognise works by artists, or even to make musical or plastic compositions. Our proposal lays aside all intentionality and only aspires to strengthen in future educators their own perceptive faculty and their audio-visual sensitivity; so that they, in turn, can release the senses of boys and girls towards a creative situation, of aesthetic experience in listening and looking.
\end{abstract}

Keywords. Modern art; early childhood; teaching; new perception; sound/silence; shadow/light.

\section{Introduction}

Artistic avant-gardes broke with the separation between the arts and with the absolute hegemony of the visual image. In their works, musicians introduce all the senses, and visual artists work with the sense of hearing, also as a receiver of plastic work. "Architectonic acoustics", is what Le Corbusier called his buildings, based on his experience in the Acropolis of Athens on his trip in 1911. "Yellow sound" Kandinsky entitled one of his scenic compositions in 1912.

If we approach a work of art, educators and children have no need for any specialist to mediate in the relationship, to interpret the work so as to help us understand its content; neither do we need any prior historic or cultural knowledge. The content of a work of modern art is in its direct perception without intermediaries. The works arrive free of predetermined content, they are not loaded with messages; they do not attempt to give

\footnotetext{
${ }^{a}$ Corresponding author: magdalena.jaume@uib.eu
} 
lessons, they do not want to reduce beholders to simple passive receivers. Barber [3, p.32] in this respect stated: "explaining that everything different, everything daring, everything that can help reflect on and to conceive new proposals is valid. We invited the public to take on their creative part, to come up on stage and integrate with us, as collaborators."

Modern works brought to the forefront the materials and techniques used, the way they were made. A painting by Leonardo does not teach how it was made. A cubist collage or a painting by Mondrian or by Pollock does. It is the very work itself that makes sure our perceptive capacity grows, opening new eyes, new ears, new touch, new skin, producing a new sensory system.

By showing how it is made, the work invites beholders to do the same; it considers they are able to produce for themselves. The work shows that it is the result of a skill shared by anybody and, potentially, by any child. Modern art is the best guide for the experimentation and generalisation of the aesthetic game, free of creeds.

Aesthetic know-how has progressed because of the artists who have followed this path. For a public brought up by academic art this proposal may be difficult, but not for children, and neither does it have to be for educators. The problems and language of modern art are easily understandable for those who already have an aroused conscious sensitivity, such as educators and children, and for those who investigate new experimentations as a tool for transforming the world.

If in our society there is aesthetic backwardness, and few intellectuals feel comfortable with the sound experience, this is mainly due to the lack of attention in previous research. The fundamental character of the work of art lies in the mystery of its timeliness. It is always present, always timely, even if it was begun decades, centuries or millennia ago.

\subsection{Benchmarks: image and sound}

Dada and the futurists are the ones who introduce sound into image. We look at, and we hear sound. Sound has a plastic character. Bustle is introduced into art as a component of metropolitan life. A piece of music by Satie written by lapses for the film by René Clair "Entre'acte". Satie composed in little jumps and juxtapositions, against harmonies and staying open to the environment and to everyday life. [2]

In the second half of the seventies, the genre directing the development of art in the western world is music, no longer painting or architecture, as it had been decades before. Fluxus, also an heir to Dada, accepts the confusion between art and life: "the integration of life into music and of music into life". Some of these works are explicit in the alloy: décoll/age-Musik. The bursting of a bulb, the noise of posters being torn from a wall, the bump of objects falling on the ground, also sounds produced by the body itself. A dripping fountain and a tray that catches each of the drops as they fall.

Light and shadow, sound and silence, movement and stability are basic, elementary characteristics in every work of art, from the most primitive beginnings. They are the material that John Cage, Merce Cunninham, Bob Wilson, László Moholy-Nagy, Alexander Calder, Llorenç Barber... work with; all of whom stand out because of their desire to expand the beholder's perceptive capacity.

\subsubsection{László Moholy-Nagy}

The works of Moholy-Nagy are made of light and shadow, of sound and of movement. They produce immaterial effects using materials that have been slightly or not at all altered.

Materials that reflect or allow themselves to be passed through and that generate a universe of luminous effects, which invade space and surround the beholder. 


\subsubsection{Alexander Calder}

The works of Calder are usually shown in museums incorrectly, in uniformly illuminated rooms, without producing shadows, and immobile. It is the never-ending, overlapping flight of the shadows on the walls that should be shown.

Calder achieves a change of scale, from small to immense, from the object that we look at to the system that surrounds us; a change of matter, from corporeal to shadow, from volume to surface, from surface to line, from line to a trail in the air.

\subsubsection{John Cage}

John Cage uses randomness to compose without controlling the resulting shape: he modifies the insides of a piano, by adding objects or altering the strings so that, in this way, he does not determine the sounds produced.

So that randomness can act, Cage makes sure several events occur at the same time, or successively, without any of them taking a leading role over the other. This means that not one of his acts is ever repeated and they are always new and unexpected. "My purpose is not to impose a certain attitude on listeners, but rather to convince them that there are sounds and that these deserve, whatever they are, to be listened to." [1 p. 254]

Musical experience, like any aesthetic experience, always has to take place for the first time, without recognition, without repetition. "A dice throw will never abolish randomness."

\subsubsection{Llorenç Barber}

Llorenç Barber does not want to call himself a musician, but rather "an expert listener". "I am interested in the aesthetic experience we call "listening", the rest are only pieces, works, scaffolding. I am not interested in the artisanal, scriptural mode - canonical or not - of such activity, but rather that "trans" element that metamorphoses the person who experiences it." $[3$, p. 10].

Llorenç Barber is precisely devoted to drawing near to everyday objects, almost without wanting to produce works but rather noises, noises of life, of the continuous flow. Working with fundamental premises that follow the ones begun by Cage: group work from the workshop, the active consideration of the beholder, the questioning of concert halls, multidisciplinarity, action, and improvisation.

\section{Method}

By 'experimental music' it should be understood music in which nobody, let alone the composer, can foresee what will happen. We do not arrange things in order (that is the very function of the instrumental, of the utilitarian): we limit ourselves, simply, to proposing processes so that a result can be produced, whatever it is. [1, p.23].

As the beginning of each educational project we have taken one of their works. In each case, what we have proposed for observation is not the object of the work in itself, but rather the relationships that the work puts in motion around it: shadows licking and tinging objects and walls; gestures rippling the air; sound collecting and resonating in other sounds and in space. 


\section{Results. Some pieces by early childhood pupils}

\subsection{Imaginary landscapes}

A box where transparent or coloured sheets are introduced, painted by the children with scribbles, drawings and letters of what was suggested or motivated by the sound landscape they listened to. A powerful spotlight transfers the drawings and colours through the air to the wall, and the very box itself becomes a magic source of lights, shadows and colours, which the children manipulate to perceive the luminous effects.

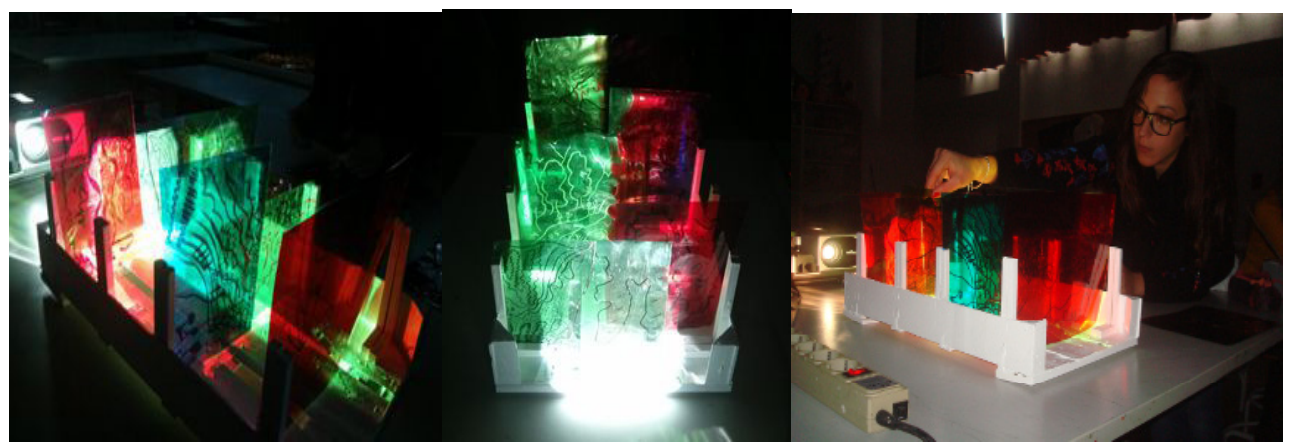

Fig. 1. Imaginary landscapes. Authors: Neus Adrover, Judith Arroyo, Margalida Reynés

\subsection{Kaleidoscope}
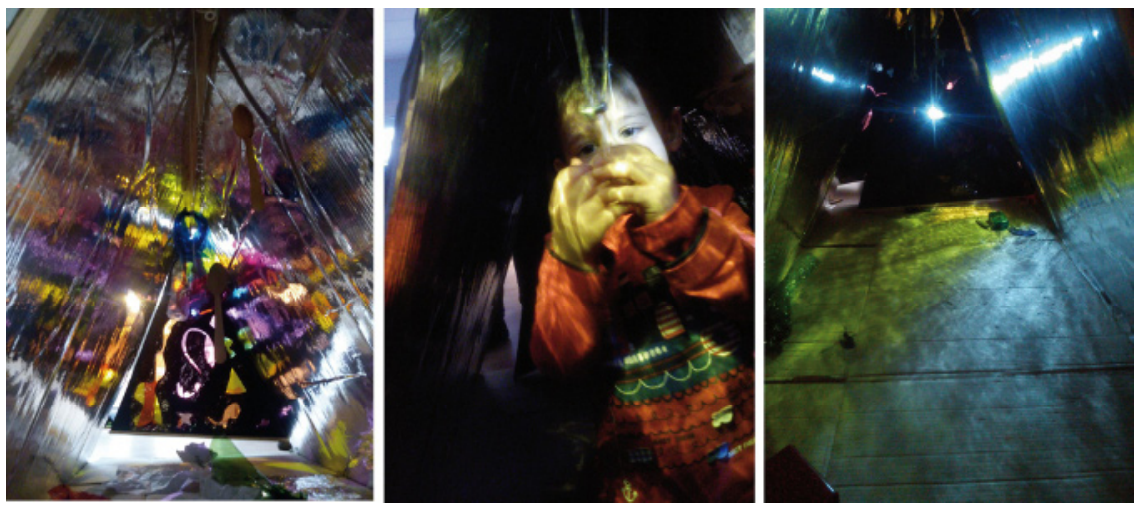

Fig. 2. Kaleidoscope: Anna Bell, Laura Hervalejo, José Antonio Orozco

Three planes form a triangular prism, with two of its walls reflecting inwards. One of the two ends is covered by a sheet with holes of different colours and shapes, whose images are seen symmetrically multiplied by twisting them from outside. 


\subsection{Bottles of light}

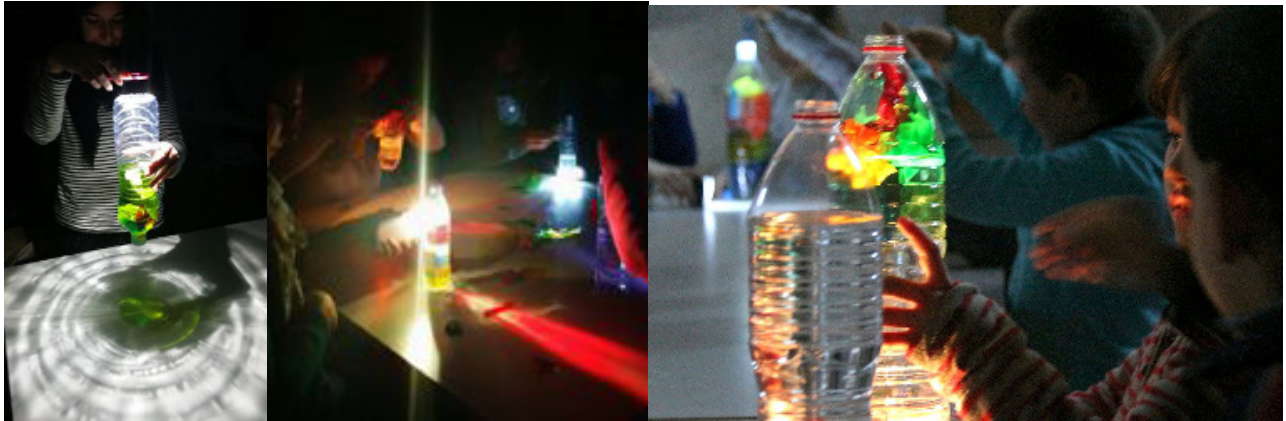

Fig. 3. Bottles of light. Authors: Tania Vidal, Natalia Darves-Bornoz, Margalida Barceló

The instrument that moves this work is intrigue and curiosity. A bottle of water with coloured papers around it. From here on everything is experimentation. By introducing pieces of paper into the bottle and mixing them in the water, some disintegrate, others overlap, generating reflections of coloured light throughout the space, with the help of a torch

\subsection{Kitchen concert}

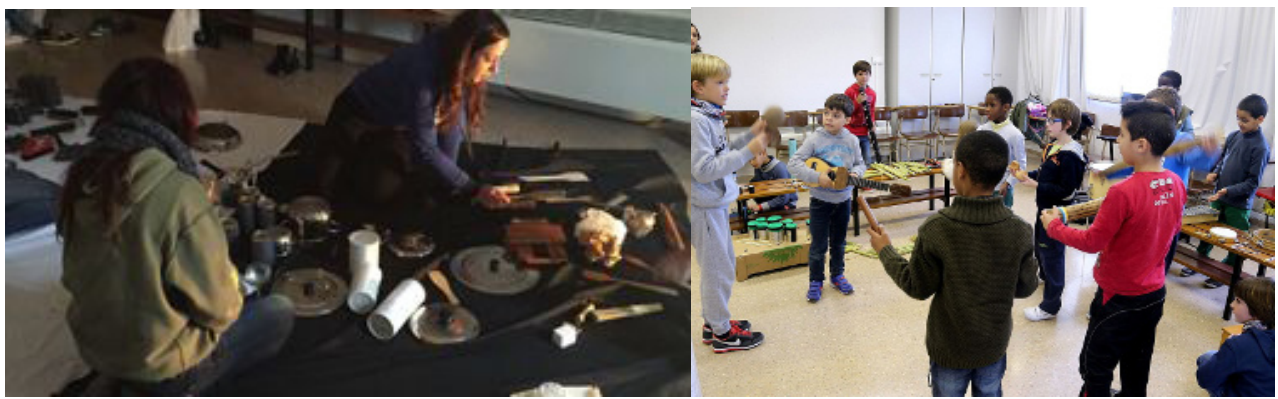

Fig. 4. Kitchen concert. Authors: Neus Adrover, Judith Rierol, Margalida Reynés

Children experiment with non-conventional materials. They relate the sounds with the ones produced by conventional musical instruments.

\subsection{Shadow imitation}
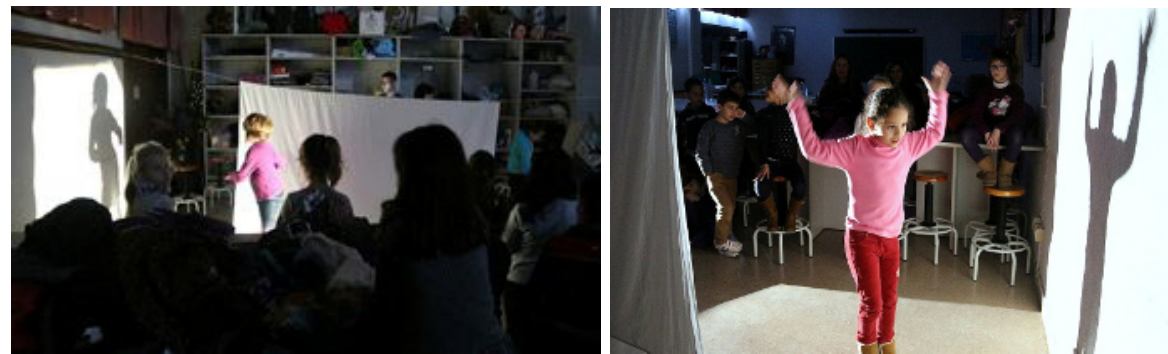

Fig. 5. Shadow imitation. Authors: Anna Bell, Laura Hervalejo, José Antonio Orozco 
Imitating the projection of a shadow. A projector on the wall; on the opposite side a mirror that reflects the wall. The child, with their back to the projector, moves and dances freely, according to the sound they hear; their shadow is projected on the wall. On the other side, facing the mirror (and with their back to the wall) another child imitates the movements of the shadow, which is reflected in the mirror.

\section{Conclusion}

The aim of our project was not to teach art, or to memorise its history, but rather to provide educator and child with a new sensorial system, a new perception of the world - not of the world of art, but of the world, directly. Because it is not art that explains the world: the world must be explained by us, people, but this will only be possible through the new perceptive senses that art has created for us.

\section{References}

1. Cage, J. Para los pájaros. México: Alias, (2010).

2. Barber, LL. Músicas de la oblicuidad, un homenaje a Carmen Pardo. In A.J. Alcázar (Ed.), La competencia artística: creatividad y apreciación crítica (pp. 113-124). Madrid: Ministerio de Educación, (2008).

3. Barber, LL. El placer de la escucha. Madrid: Ársora ediciones, (2003). 